\title{
La influencia de la Cábala en la obra de Juana García Abás y José Luis Fariñas de Cuba
}

\author{
The Influence of the Kabbalah in the Works of Juana García Abás and José Luis Fariñas of \\ Cuba
}

\author{
Stephen Sadow \\ stephensadow@gmail.com
}

\section{Resumen:}

Este estudio trata de la obra de Juana García Abás y José Luis Fariñas, dos judío-cubanos contemporáneos, y cómo su arte es imbuido por la Cábala. La poesía de García Abás, discutida aquí, es poeta es muy compleja, pero sigue una lógica cabalista en su exploración de cómo funciona el universo. Como los textos cabalísticos, esta poesía no es lineal; es una fusión de símbolos y referencias poco conocidas se relacionan en maneras poco esperadas. Fariñas es un dibujante y acuarelista y poeta también que posea un entendimiento muy personal de la Cábala. Presenta los conceptos cabalistas en una forma idiosincrásica y que a primera vista a menudo parece extraña. Sus figuras demandan la interpretación del veedor tanto como del lector del los textos medievales y oscuros.

La Cábala - Cuba - Poesía judía Arte judía - García Abás - Fariñas

\begin{abstract}
:
This study treats the work of Juana García Abás y José Luis Fariñas, two contemporary Cuban-Jew and how in their art is imbued with the Kabbalah. García Abás' poetry, discussed here, is very complex, but it follows a Kabbalistic logic in its exploration to how the universe functions. Like the Kabbalistic texts, this poetry is not linear; it is a fusion of symbols and little-known references relate to each other in unexpected ways. Fariñas, a drawer, watercolorist and also a poet, possesses a very personal understanding of the Kabbalah. He presents it's concepts in idiosyncratic ways, that at first sight, often seem strange. His figures demand the interpretation of the viewer in a way that that mimics the reader of obscure medieval texts.

Kabbalah - Cuba -Jewish Poetry - Jewish Art - García Abás - Fariñas
\end{abstract}




\section{La influencia de la Cábala en las obras de Juana García Abás y José Luis Fariñas de Cuba}

La Cábala judía influye intensamente la poesía y el arte visual de dos cubanos, madre e hijo, Juana García Abás y José Luis Fariñas. ${ }^{1}$ En este aspecto, son singulares en la historia de las artes cubanas En su poemario Arqueología sagrada, publicado como parte de su libro Circunloquio, ${ }^{2}$ García Abás infunde su poesía con conceptos cabalistas igual que lo hace Fariñas en sus dibujos, acuarelas y pinturas tanto como en sus poemas. Tienen un lugar importante en el panorama artístico judíolatinoamericano. $^{34}$

Juana García Abás nació en La Habana en 1950. Es poeta judía-cubana de ascendencia sefardita. Ha trabajado como periodista y crítica de arte. Sus primeros guías en la escritura de la poesía fueron José Lezama Lima y Roque Dalton. Ella es miembro de la Unión de Escritores y Artistas de Cuba. En 2006. le fue otorgado el Premio Nacional de Poesía "Nicolás Guillén," uno de los honores literarios cubanos más importantes, por su antología Circunloquio. ${ }^{5}$

José Luis Fariñas, su hijo nacido en 1972, es un artista y poeta judío-cubano. Su obra pictórica — en su mayoría dibujo y acuarela — es de primer nivel. Es conocido internacionalmente y representado por las prestigiosas galerías Miyako Yoshinaga en Nueva York y Avistamientos en La Habana. Su producción varía entre el arte e ilustraciones para numerosas ediciones del Instituto Cubano del Libro y ediciones españolas de alta bibliofilia para Ars Liber de Don Quixote de la Mancha, El Apocalipsis de San Juan y Fausto de Goethe, así como retratos de José Martí y Fidel Castro.

Resumir la teosofía de La Cábala y su multitud de interpretaciones quedan más allá del ámbito de este estudio. Es suficiente decir que influencia del Sefer Yetsirá, siglo II, el Zohar, una antología de pensamientos cabalistas medievales de Moisés de León. en España a fines del siglo XIII, y La Cábala de Isaac Luria, del Eretz Israel del siglo están presentes en los poemas y el arte estudiado aquí.

${ }^{1}$ Les agradezco a Juana García Abás y José Luis Fariñas por su generosidad.

${ }^{2}$ Para estudios de Circunloquio en su totalidad, véase López Lemos y Lozada Guevera.

${ }^{3}$ Que sepa yo, García Abás y Fariñas son los únicos estudiosos de La Cábala en Cuba Hay escritores y artistas plásticos de otros países latinoamericanos cuya obra muestra la influencia de La Cábala cada uno en su manera personal. Los más prominentes son: Angelina Muñiz-Huberman, Esther Pelignos, Jenny Asse Chayo de México; Leonor Coifman, Patricia Krasbuch, Carlos Azulay de Argentina; Ricardo Barnatán y Mario Satz de Argentina/España; Isaac Goldemberg de Perú/EEUU;

y Rubén Kanelenstein del Uruguay.

${ }^{4}$ Que sepa yo, García Abás y Fariñas son los únicos estudiosos de La Cábala en Cuba Hay escritores y artistas plásticos de otros países latinoamericanos cuya obra muestra la influencia de La Cábala cada unp en su manera personal. Los más prominentes son: Angelina Muñiz-Huberman, Esther Seligson, Jenny Asse Chayo de México; Leonor Coifman, Patricia Krasbuch, Carlos Azulay de Argentina; Ricardo Barnatán y Mario Satz de Argentina/España; Isaac Goldemberg de Perú/EEUU;

y Rubén Kanelenstein del Uruguay.

${ }^{5}$ Para una entrevista biográfica de Juana García Abás, véase Bevedia. 
Hay ciertas invenciones de La Cábala que aparecen y reaparecen en la obra de García Abás y Fariñas. El más importante es Adam Cadmon, el hombre primordial, la figura antropomórfica de Dios. Es el creador desde el cual fluye constantemente la luz de las diez sefirot o emanaciones divinas. Cuando están emitidas de Adam Cadmon, las sefirot están contenidas en recipientes, unos fuertes y otros que se rompen, dejando caer la luz que llevan. Esta luz se contamina con el lodo, es decir, el Mal.

El Zohar presenta las emanaciones en balance, en interacción y en contradicción entre sí. (Green, pp. 65-68.) En From Metaphysics to Midrash, Shaul Maggid describe la complejidad extrema del sistema luriana que extiende el pensamiento de los textos anteriores. El proceso es infinito. Admite paradojas y contradicciones que existen a la vez. Todo es metamorfosis y cambio continúo. (Maggid, pp. 15-33)

Según Luria, es la tarea del hombre ayudarle a Dios a reparar el mundo (el Ticún Olom \} rescatando, por su devoción y sus actos a la humanidad, las partículas de luz. Este ciclo se repite eternamente dentro del ser humano y en el ain sof (lo infinito). (Scholem, p. 209, Kaplan, p. 54, Dunn, p. 168, Schwartz)

En su poesía, García Abás es una mística, cosmóloga y visionaria que reinterpreta los principios básicos de la Cábala. Ella explica sin ambages "temas de cábala mística judaica, ética y dialéctica, y aspectos capitales de la crisis física en la concepción del multiverso. (García Abás, 2015, p. 1). Un reto.

La Cábala está presente por todo Circunloquio y singularmente sobresalida en los veintidós poemas de "Arqueología sagrada," la quinta sección de la colección. Con la mística judía y un toque de la física cuántica, García Abás crea su propio cosmos poético.

El énfasis dialéctico en esta poesía la hace distinta y fascinante. García Abás es una poeta mística y neo-marxista. En su poesía, hay paradojas por todas partes. Elementos contrarios que se podrían repeler, en ella se integran. Tesis, antítesis y síntesis pueden aparecer como reacciones en cadena in fieri, que todavía no han llegado a ser y están en proceso; la negación sigue a la negación. (García Abás, 2015, 1) Para ellas, este proceso se ve metafóricamente en la genética moderna: ella dice "Las cadenas repiten la cromatina helicoidal, el hélix", el hélix doble. (García Abás, 2006, p. 192). La suya es una dialéctica que no se enfoca en ascenso espiral alguno, sino como una manera de asimilar y reflejar su multiverso. La poeta y crítica cubana Fina García Marruz comenta que García Abás "ha superado la difícil conciliación entre el Materialismo Filosófico y la tradición bíblica. (García-Marruz, p. 4)

Como todos los textos cabalísticos, esta poesía no es lineal; es una fusión de símbolos y referencias poco conocidas se relacionan en maneras poco esperadas, dentro de cada poema y entre ellos. Los conceptos místicos están dispersos de poema en poema. En "Mmística" ella observa: "Ando extraviada: estoy en todas partes”. (García Abás, 2006, 2) 
Esta poesía a menudo es oscura, asociativa y a veces parece hermética. Por todas partes hay referencias a sistemas cosmológicos que influyeron el desarrollo de los conceptos, sean griegos, romanos, gnósticos, o del cristianismo medieval. Palabras específicamente católicas actúan como un anti-lenguaje en esta poesía judía: "prelado," "resurrección," “votivo." El vocabulario de García Abás es extremadamente sofisticado ("ordalía", "volatinero que urde escalas"), y sus referencias frecuentes a la flora y fauna cubanas, mientras dan una precisión inmediata a lo nombrado, remite a los lectores no caribeños a diccionarios especializados. Es lógico que el simbolismo místico no permita interpretaciones definitivas. Sin embargo, esta poesía le provoca al lector contemplar, hacer asociaciones y pensar en su propia visión del cosmos.

Juana García Abás insiste en que, de toda La Cábala, el libro que más le impacta es el Sefer Yetsirá (García Abás, Comunicación personal, 25 de mayo, 2015). Ella elabora una descripción del Ain Sof (Dios en tanto infinito sin límites ni limitaciones) y las diez sefirot, emanaciones divinas, cada una con cualidades específicas que brotan del Ein Sof. Entre ellas, hay Hod (Esplendor) y las fuerzas en equilibrio de Jesed (Amor) y Din (Juicio). Además, el texto contiene una serie compleja de evocaciones de la gematría, basadas en los equivalentes numéricos de las veintidós letras hebreas y las sefirot, para demostrar la verdad incontrovertible de la fuerza creativa de Dios Las pruebas de la Yetsirá son absolutamente estables y armónicas: internamente consistentes y sin error en las calculaciones, como diría un matemático.

Muchos de los poemas de García Abás sí que relejan el Sefer Yetsirá, incluso los que no pertenecen a "Antología sagrada". Por ejemplo, las letras hebreas aparecen con frecuencia. El epígrafe de "Testimonio": "Cuando el álef precede la letra del nombre" (García Abás, 2006, p. 30) viene directamente de ese volumen. En el mismo poema ella amplifica el concepto: "Las egresan a sus fuentes y que los opuestos se repelen, pero que pueden ser reconciliados a sí mismos. (García Abás, 2006, p. 37)

Algunos poemas mantienen los aspectos asociativos y celebratorios del Zohar., "Textus" dice:

La imagen de lo posible canta y cuenta la raíz de la que nada puede predicarse, con su núcleo de nuez tras cuatro pieles de fuego negro sobre fuego blanco. Porque lo que está abajo, está arriba;

lo que está adentro, está afuera y algo permanece donde todo cambia en cadena sin fin, cuando la hormiga, alzando un grano de mostaza ordena un cisma en Alfa del Centauro. ${ }^{6}$

(García Abás, 2006, p. 193)

\footnotetext{
${ }^{6}$ Con todos sus poemas, García Abás utiliza el margen izquierdo, tal vez, una ilusión oblicua a la escritura del hebreo.
} 
Este poema es afirmativo. Habla de la creación desde la nada y luego agrega el símbolo de la nuez, duro afuera, delicioso adentro, aludiendo también a las capas de interpretación de los textos sagrados. García Abás enfatiza, "La imagen esencial de "Fuego negro sobre fuego blanco," (o letras sobre pergamino) aparecida por primera vez en el Talmud, ha sido interpretada por comentaristas por los milenios. Yo prefiero la idea que "el fuego negro representa lo intelectual en tanto natural; mientras los espacios blancos representan lo que va más allá del mundo del intelecto". (García Abás, 2002, p. 1) Energías sin límites están en movimiento constante hasta que las direcciones espaciales pierden su sentido. Cualquier acción afecta todo; el trabajo de una hormiga afecta una galaxia muy distante. Todo está interconectado.

En varios poemas, García Abás emplea los quarks de la física cuántica como una metáfora por la luz móvil cabalística. En la descripción cuántica del universo, las partículas quarks "arriba" y "abajo", se mueven simultáneamente. Las partículas se atraen o se repelen, de acuerdo a sus cargas. Y, más importante, los electrones viajan en rutas circulares. (Rae, p.13) En "Cábala", la poeta observa "Todo emana de un punto y a ese punto retorna." (García Abás, 2006, p. 191)

El proceso del pensamiento dialéctico tiene mucho en común con el desarrollo nunca terminado, infinito, encontrado dentro de la Cábala de Isaac Luria del siglo dieciséis. "Aviso," dice: "Todo nace con el riesgo de ser vuelto al revés." (García Abás, 2006, p. 303) En "El arca” ella explica:

Conviene descifrar las aporías — saber qué piensa Dios—, tomar la ruta insólita. Si el infinito es un continuo con la belleza de lo inevitable, el desvío triunfa donde naufragan los sistemas,

los cánones $(\ldots)$ (García Abás, 2006, 21)

Las paradojas pueden ser descifradas, si se toma esa ruta desconocida que las concilia. El desvío es la clave de la creación: el cambio, lo diacrítico que enriquece la experiencia, allí donde lo inamovible fracasa.

En "Arqueología sagrada", las sefirot sirven como metáforas complejas por aspectos conectados, si bien antitéticos, de las cualidades divinas y sus potenciales. En "Alumbramiento," García Abás describe la relación eterna entre las tres emanaciones más influyentes: “...bifurcado en Binah y Chochmah desde la luz -Kéter.” (García Abás, 2006, p. 250)

Kéter, la más alta de las tres, difunde la luz que rompe la conexión natural entre Binah (Entendimiento) y Chochmah (Sabiduría). "De Kéter a Maljut" empieza con la transgresión de mezclar fibras, una prohibición talmúdica y luego enfrenta imágenes de oposición; algunas de ellas desafían al lector:

Mezcla de lana y lino, aleja tu rostro al que asomas ese doble júbilo que violenta límites 
enraizado en su origen, como el aire a la llama, ... hacia el aura de la corona. . (García Abás, 2006, p. 186)

Maljut se sienta al fondo de la forma antropomórfica de las sefirot. En la cábala luriana, ésta es la sefirá más compleja de todas. (Dunn,102) De Maljut se desarrolla la Shejiná, el aspecto femenino de Dios, en sus muchos papeles como madre, novia y, especialmente, una exiliada misma que relaciona a todos los exiliados:

Hay un orden proscrito que se exilia en los desastres de lo manifiesto, cuando lo esotérico se confina distanciado de ti, décima sefirá —y hasta de sí-, en lo finito (. . .)

(García Abás, 2006, 196)

La Shejiná tiene también un lado oscuro y cambiante. (Scholem, p. 27, Muñiz-Huberman, p. 54)

Además, recurre en esta poesía el concepto luriano de las Shevirat HaKelim, el "hacerse pedazos de los recipientes". Encerrada en los cántaros, la luz de cada una de las sefirot cae a la Tierra; Keter, Binah, y Chochmah llegan intactas. Las otras se rompen y su luz se dispersa por todos lados. Y dentro de esta luz, existen partículas que llevan el sufrimiento y un tipo nuevo del exilio que es una separación del ser humano del Ain Sof. "Ázimos” declara:

Diásporas y masacres con azares de ciervo desentrañan la redención que anuncian los exilios del cuerpo y los del alma. (García Abás, 2006, 37)

Estos exilios son de Edén, del Israel anciano, de España y, en particular, del Ain Sof. Y García Abás da énfasis al concepto del exilio por la forma de los poemas, poniéndolos a la derecha de la página impresa, es decir, fuera de su lugar.

No obstante, la situación no es desesperada. En un poema con un título paradójico, "Del ordenado caos", García Abás asegura que "El infinito sostiene sus exilios." (García Abás, 2006, 262). El ser humano tiene que ayudarle al Ein Sof en restablecer la bondad del universo. "Crisol" explica:

Será tu sino develar lo envuelto

y expulsar la otra parte con la lezna del zapatero que une a los cueros de encima y debajo, el cielo y la tierra entre nadires ignorados por el orante ingenuo.

Tú expulsarás la otra parte, el sitra atra; un orante ingenuo, no. 
Siempre hay la oportunidad por Ticún Olam, el reparar del mundo. El ser humano expulsará el sitra atra, la otra parte, el Mal. Y así inspirar la venida del Mesías. De hecho, el poema "Mesías", describe la elección: "El aire se corrompe tras los óleos rojos/— todos fuimos ungidos/Sólo a uno se le muestra el camino." (García Abás, 2006, p. 210)

En el poema "Circunloquio", García Abás resume su cosmología, pero esta vez lo hace en términos científicos:

Esta pizca de sal para el café de monte enlaza pulsares (. . .) la energía oscura invierte su coágulo invisible y dispone el concierto del cometa y del quark.

(...) ni difieran los cuantos de los cuásares.

(García Abás, 2006, p. 302)

No es sorprendente que la física aquí relevante trate de la luz en sus muchas formas. El título de un poema es "Pan, mostaza y quark" - sustento, sabor y ser. Otro poema habla de ondas de radio siendo lanzadas hacia el espacio profundo. Un pulsar es una estrella rotativa que emita rayos de radiación electromagnética. Hay una hipótesis que supone que los cuásares podrían contener adentro huecos negros de billones de veces la masa del sol. Aunque la luz no puede escapar de los huecos negros mismos, unas ondas de radio pueden liberarse por los bordes. (Rae, 13) ¿Los cántaros rotos? La energía oscura es un tipo de energía desconocida. La hipótesis es que permea todo el espacio, con la tendencia de acelerar la expansión del universo. ¿El Ein Sof? Los cometas y los quarks se revuelven en círculos o parábolas. (Rae, p. 71) ¿“Todo emana de un punto y a ese punto retorna"? (García Abás. 2006, p. 197)

En contraste de esa complejidad, las obras temprana de Fariñas representan, con un realismo estilizado, el patriarca Abraham y el profeta Ezequiel. Además. su retrato de la heroína Rut está expuesto en el hotel del mismo nombre en La Habana. ${ }^{7}$

Según él, su arte lleva las influencias de Goya, Leonardo, Dürer, Doré, Brueghel, Bosch, Antonia Eiriz, Servando Cabrera, Rembrandt, Munch, Van Gogh, Rodin, Hiroshigue. (Comunicación personal, 12 de diciembre, 2017). Sus técnicas preferidas son el dibujo y la acuarela, ambas las realiza a pincel extrafino, y también pinta al óleo sobre lienzo.

El arte más desarrollado de Fariñas es único, idiosincrásico, extraño a primera vista, no inteligible por muchos veedores. La calidad evocadora de sus obras inspira una reacción afectiva y un deseo, a menudo frustrado, de entender el contenido. Se cree ver características surrealistas u oníricas, pero éstas no existen. El suyo es un arte visionario, y a veces apocalíptico (hasta creó una serie de grabados derivados del tema de el Apocalipsis Final. Fariñas tiene un entendimiento muy personal de la Cábala. García Abás comenta, "las formas periféricas, marginales, se transmutan, durante el período de observación, en interiores o viceversa, de acuerdo a la aprehensión personal del espacio

${ }^{7}$ Para una nota sobre una etapa en el desarrollo del arte de Fariñas, véase Yoshinaga. 
y de las formas que lo pueblan, o según se manifieste la relación entre el fenómeno figurativo y la subjetividad del perceptor." (García Abás, 2002, 2).

Eliot Wolfson, en Through a Speculum That Shines: Vision and Imagination in Medieval Jewish Mysticism, dice los cabalistas de la imaginación extraordinaria en la exégesis de textos sagrados. (Wolfson, 279-80.) Esto aplica al modo de trabajar de Fariñas. Él lee los textos sagrados y contesta con una imaginación que tiene mucho que ver con la de los místicos judíos. García Abás insiste que "el tema de la rotura de los recipientes está prácticamente en toda su obra como la idea de un Adam Cadmon, que es muy recurrente en sus esencias". (J. García Abás, Comunicación personal, 25 de mayo de 2015.)

José Luis Fariñas explica "Pretendo mostrar a través de símbolos cabalísticos y alusiones a los textos sagrados y a los místicos, en parte sacros, la concepción de un cosmos donde pareciera redimirse la condición caótica en la ilimitada capacidad de transformación del ser y de su espacio, gracias a la acción del desvío que incide generando espacios de crisis en la naturaleza y en la sociedad". (Fariñas y García Abás. 2005,1)

Fariñas me escribió "Siempre me inspiraron temas de la mística, pero más después de recibir de mi madre tanta inspiración y poesía a través de su reinterpretación de la Cábala como filosofía mística ... Los recipientes rotos, la fuerza transmutativa del Verbo, el esplendor y la esencia indescriptible de Dios, el caos de las letras del Zohar al inicio del tiempo cuando poco a poco este se iba conformando en textos según sucedían los acontecimientos." (J. L Fariñas, Comunicación personal, 16 de abril de 2017)

Aquí, son relevantes las investigaciones de Wolfson sobre lo visual en El Zohar. (Wolfson) X Pero los cabalistas escribían en prosa sus comentarios sobre los misterios del cosmos. Como artista plástico, Fariñas va más allá de los cabalistas. Su manera de interpretar es pura exégesis visual. dibuja y pinta con óleos y acuarelas para representar sus interpretaciones de conceptos cabalistas.

En el Zohar, Adam Cadmon es mítico: el hombre primordial. Tiene una forma casi antropomórfica. Aquí, Adam Cadmon mismo está en desarrollo: parece una crisálida. Las partes de su cuerpo, incluyendo su cara, no están terminadas. Hay cosas extrañas que se expelan. Se supone que evolucionará a la figura que desde los orificios de su "cuerpo" salen las emanaciones. Algunos poemas mantienen los aspectos asociativos y celebratorios del Zohar., "Textus", dice:La imagen de lo posible canta y cuenta

la raíz de la que nada puede predicarse, con su núcleo de nuez tras cuatro pieles de fuego negro sobre fuego blanco. Porque lo que está abajo, está arriba; lo que está adentro, está afuera y algo permanece donde todo cambia en cadena sin fin, cuando la hormiga, alzando un grano de mostaza 
ordena un cisma en Alfa del Centauro. ${ }^{8}$

(García Abás, 2006, p. 193)

Este poema es afirmativo. Habla de la creación desde la nada y luego agrega el símbolo de la nuez, duro afuera, delicioso adentro, aludiendo también a las capas de interpretación de los textos sagrados. García Abás enfatiza, "La imagen esencial de "Fuego negro sobre fuego blanco," (o letras sobre pergamino) aparecida por primera vez en el Talmud, ha sido interpretada por comentaristas por los milenios. Yo prefiero la idea que "el fuego negro representa lo intelectual en tanto natural; mientras los espacios blancos representan lo que va más allá del mundo del intelecto". (García Abás, 2002, p. 1) Energías sin límites están en movimiento constante hasta que las direcciones espaciales pierden su sentido. Cualquier acción afecta todo; el trabajo de una hormiga afecta una galaxia muy distante. Todo está interconectado.

En varios poemas, García Abás emplea los quarks de la física cuántica como una metáfora por la luz móvil cabalística. En la descripción cuántica del universo, las partículas quarks "arriba" y “abajo", se mueven simultáneamente. Las partículas se atraen o se repelen, de acuerdo a sus cargas. Y, más importante, los electrones viajan en rutas circulares. (Rae, p.13) En "Cábala", la poeta observa "Todo emana de un punto y a ese punto retorna." (García Abás, 2006, p. 191)

El proceso del pensamiento dialéctico tiene mucho en común con el desarrollo nunca terminado, infinito, encontrado dentro de la Cábala de Isaac Luria del siglo dieciséis. "Aviso," dice: "Todo nace con el riesgo de ser vuelto al revés." (García Abás, 2006, p. 303) En "El arca” ella explica:

Conviene descifrar las aporías — saber qué piensa Dios—, tomar la ruta insólita. $\mathrm{Si}$ el infinito es un continuo con la belleza de lo inevitable, el desvío triunfa donde naufragan los sistemas, los cánones $(\ldots)$ (García Abás, 2006, 21)

Las paradojas pueden ser descifradas, si se toma esa ruta desconocida que las concilia. El desvío es la clave de la creación: el cambio, lo diacrítico que enriquece la experiencia, allí donde lo inamovible fracasa.

En "Arqueología sagrada", las sefirot sirven como metáforas complejas por aspectos conectados, si bien antitéticos, de las cualidades divinas y sus potenciales. En "Alumbramiento," García Abás describe la relación eterna entre las tres emanaciones más influyentes: “...bifurcado en Binah y Chochmah desde la luz -Kéter.” (García Abás, 2006, p. 250)

Kéter, la más alta de las tres, difunde la luz que rompe la conexión natural entre Binah (Entendimiento) y Chochmah (Sabiduría). "De Kéter a Maljut" empieza con la transgresión de

\footnotetext{
${ }^{8}$ Con todos sus poemas, García Abás utiliza el margen izquierdo, tal vez, una ilusión oblicua a la escritura del hebreo.
} 
mezclar fibras, una prohibición talmúdica y luego enfrenta imágenes de oposición; algunas de ellas desafían al lector:

Mezcla de lana y lino, aleja tu rostro al que asomas ese doble júbilo que violenta límites enraizado en su origen, como el aire a la llama, ... hacia el aura de la corona... (García Abás, 2006, p. 186)

Maljut se sienta al fondo de la forma antropomórfica de las sefirot. En la cábala luriana, ésta es la sefirá más compleja de todas. (Dunn,102) De Maljut se desarrolla la Shejiná, el aspecto femenino de Dios, en sus muchos papeles como madre, novia y, especialmente, una exiliada misma que relaciona a todos los exiliados:

Hay un orden proscrito que se exilia en los desastres de lo manifiesto, cuando lo esotérico se confina distanciado de ti, décima sefirá —y hasta de sí-, en lo finito (. . .)

(García Abás, 2006, 196)

La Shejiná tiene también un lado oscuro y cambiante. (Scholem, p. 27, Muñiz-Huberman, p. 54)

Además, recurre en esta poesía el concepto luriano de las Shevirat HaKelim, el "hacerse pedazos de los recipientes". Encerrada en los cántaros, la luz de cada una de las sefirot cae a la Tierra; Keter, Binah, y Chochmah llegan intactas. Las otras se rompen y su luz se dispersa por todos lados. Y dentro de esta luz, existen partículas que llevan el sufrimiento y un tipo nuevo del exilio que es una separación del ser humano del Ain Sof. "Ázimos” declara:

Diásporas y masacres con azares de ciervo desentrañan la redención que anuncian los exilios del cuerpo y los del alma.

(García Abás, 2006, 37)

Estos exilios son de Edén, del Israel anciano, de España y, en particular, del Ain Sof. Y García Abás da énfasis al concepto del exilio por la forma de los poemas, poniéndolos a la derecha de la página impresa, es decir, fuera de su lugar.

No obstante, la situación no es desesperada. En un poema con un título paradójico, "Del ordenado caos", García Abás asegura que "El infinito sostiene sus exilios." (García Abás, 2006, 262). El ser humano tiene que ayudarle al Ein Sof en restablecer la bondad del universo. "Crisol” explica:

Será tu sino develar lo envuelto y expulsar la otra parte 
con la lezna del zapatero que une a los cueros de encima y debajo, el cielo y la tierra entre nadires ignorados por el orante ingenuo.

Tú expulsarás la otra parte, el sitra atra; un orante ingenuo, no.

(García Abás, 2006, p. 203)

Siempre hay la oportunidad por Ticún Olam, el reparar del mundo. El ser humano expulsará el sitra atra, la otra parte, el Mal. Y así inspirar la venida del Mesías. De hecho, el poema "Mesías", describe la elección: "El aire se corrompe tras los óleos rojos/—-todos fuimos ungidos/Sólo a uno se le muestra el camino." (García Abás, 2006, p. 210)

En el poema "Circunloquio", García Abás resume su cosmología, pero esta vez lo hace en términos científicos:

Esta pizca de sal para el café de monte enlaza pulsares (...) la energía oscura invierte su coágulo invisible y dispone el concierto del cometa y del quark. (...) ni difieran los cuantos de los cuásares.

(García Abás, 2006, p. 302)

No es sorprendente que la física aquí relevante trate de la luz en sus muchas formas. El título de un poema es "Pan, mostaza y quark" - sustento, sabor y ser. Otro poema habla de ondas de radio siendo lanzadas hacia el espacio profundo. Un pulsar es una estrella rotativa que emita rayos de radiación electromagnética. Hay una hipótesis que supone que los cuásares podrían contener adentro huecos negros de billones de veces la masa del sol. Aunque la luz no puede escapar de los huecos negros mismos, unas ondas de radio pueden liberarse por los bordes. (Rae, 13) ¿Los cántaros rotos? La energía oscura es un tipo de energía desconocida. La hipótesis es que permea todo el espacio, con la tendencia de acelerar la expansión del universo. ¿El Ein Sof? Los cometas y los quarks se revuelven en círculos o parábolas. (Rae, p. 71) ¿"Todo emana de un punto y a ese punto retorna"? (García Abás. 2006, p. 197)

En contraste de esa complejidad, las obras temprana de Fariñas representan, con un realismo estilizado, el patriarca Abraham y el profeta Ezequiel. Además. su retrato de la heroína Rut está expuesto en el hotel del mismo nombre en La Habana. ${ }^{9}$

Según él, su arte lleva las influencias de Goya, Leonardo, Dürer, Doré, Brueghel, Bosch, Antonia Eiriz, Servando Cabrera, Rembrandt, Munch, Van Gogh, Rodin, Hiroshigue. (Comunicación personal, 12 de diciembre, 2017). Sus técnicas preferidas son el dibujo y la acuarela, ambas las realiza a pincel extrafino, y también pinta al óleo sobre lienzo.

El arte más desarrollado de Fariñas es único, idiosincrásico, extraño a primera vista, no inteligible por muchos veedores. La calidad evocadora de sus obras inspira una reacción afectiva y un deseo, a

${ }^{9}$ Para una nota sobre una etapa en el desarrollo del arte de Fariñas, véase Yoshinaga.

Cuadernos Judaicos ISSN: 07188749

№36 -Diciembre 2019 
menudo frustrado, de entender el contenido. Se cree ver características surrealistas u oníricas, pero éstas no existen. El suyo es un arte visionario, y a veces apocalíptico (hasta creó una serie de grabados derivados del tema del el Apocalipsis Final. Fariñas tiene un entendimiento muy personal de la Cábala. García Abás comenta, "las formas periféricas, marginales, se transmutan, durante el período de observación, en interiores o viceversa, de acuerdo a la aprehensión personal del espacio y de las formas que lo pueblan, o según se manifieste la relación entre el fenómeno figurativo y la subjetividad del perceptor." (García Abás, 2002, 2).

Eliot Wolfson, en Through a Speculum That Shines: Vision and Imagination in Medieval Jewish Mysticism, dice los cabalistas de la imaginación extraordinaria en la exégesis de textos sagrados. (Wolfson, 279-80.) Esto aplica al modo de trabajar de Fariñas. Él lee los textos sagrados y contesta con una imaginación que tiene mucho que ver con la de los místicos judíos. García Abás insiste que "el tema de la rotura de los recipientes está prácticamente en toda su obra como la idea de un Adam Cadmon, que es muy recurrente en sus esencias". (J. García Abás, Comunicación personal, 25 de mayo de 2015.)

José Luis Fariñas explica "Pretendo mostrar a través de símbolos cabalísticos y alusiones a los textos sagrados y a los místicos, en parte sacros, la concepción de un cosmos donde pareciera redimirse la condición caótica en la ilimitada capacidad de transformación del ser y de su espacio, gracias a la acción del desvío que incide generando espacios de crisis en la naturaleza y en la sociedad". (Fariñas y García Abás. 2005,1)

Fariñas me escribió "Siempre me inspiraron temas de la mística, pero más después de recibir de mi madre tanta inspiración y poesía a través de su reinterpretación de la Cábala como filosofía mística ... Los recipientes rotos, la fuerza transmutativa del Verbo, el esplendor y la esencia indescriptible de Dios, el caos de las letras del Zohar al inicio del tiempo cuando poco a poco este se iba conformando en textos según sucedían los acontecimientos." (J. L Fariñas, Comunicación personal, 16 de abril de 2017)

Aquí, son relevantes las investigaciones de Wolfson sobre lo visual en El Zohar. (Wolfson) X Pero los cabalistas escribían en prosa sus comentarios sobre los misterios del cosmos. Como artista plástico, Fariñas va más allá de los cabalistas. Su manera de interpretar es pura exégesis visual. dibuja y pinta con óleos y acuarelas para representar sus interpretaciones de conceptos cabalistas.

En el Zohar, Adam Cadmon es mítico: el hombre primordial. Tiene una forma casi antropomórfica. Aquí, Adam Cadmon mismo está en desarrollo: parece una crisálida. Las partes de su cuerpo, incluyendo su cara, no están terminadas. Hay cosas extrañas que se expelan. Se supone que evolucionará a la figura que desde los orificios de su "cuerpo" salen las emanaciones. 


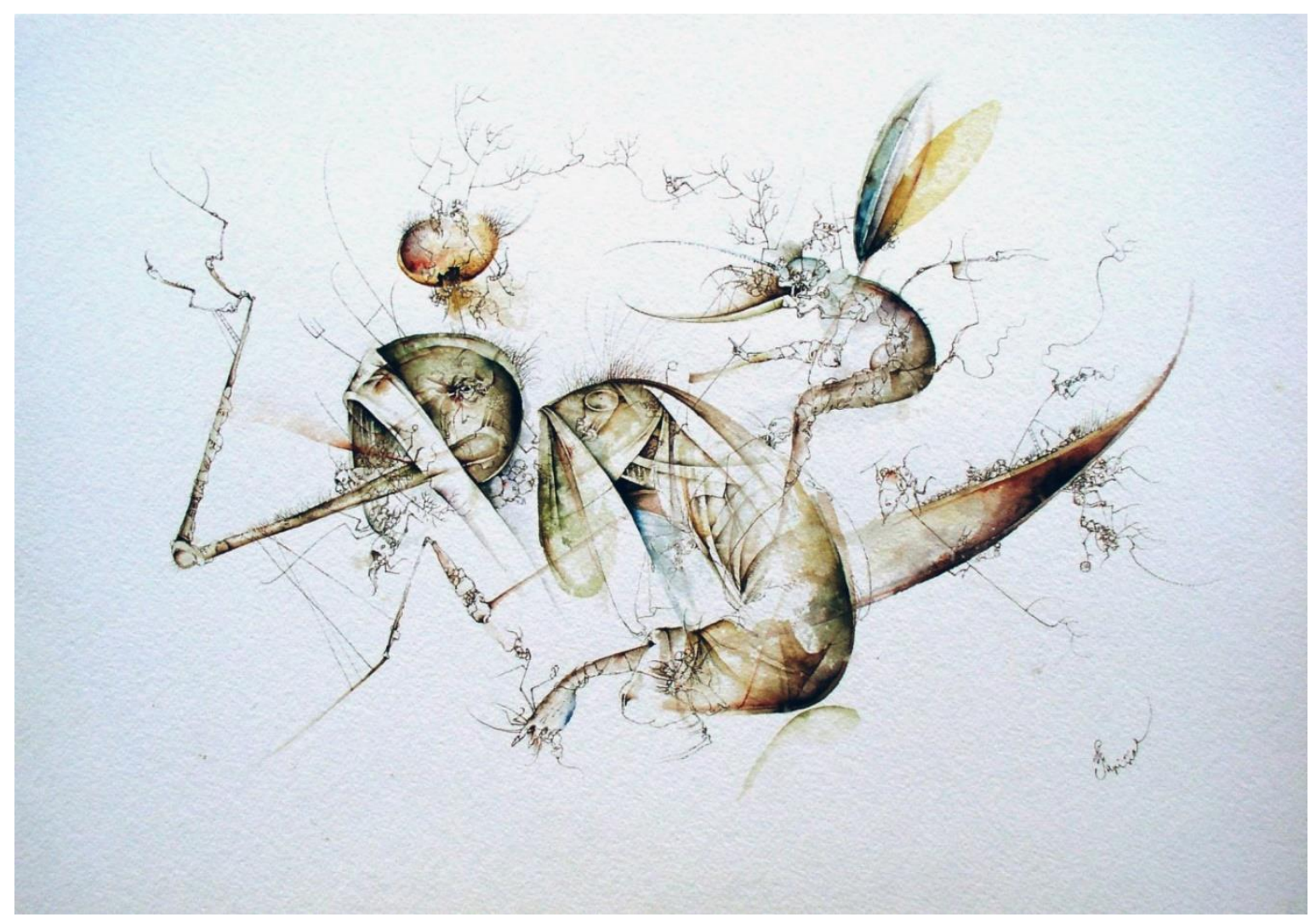

Adam Cadmon. J. L. Fariñas. 1999 


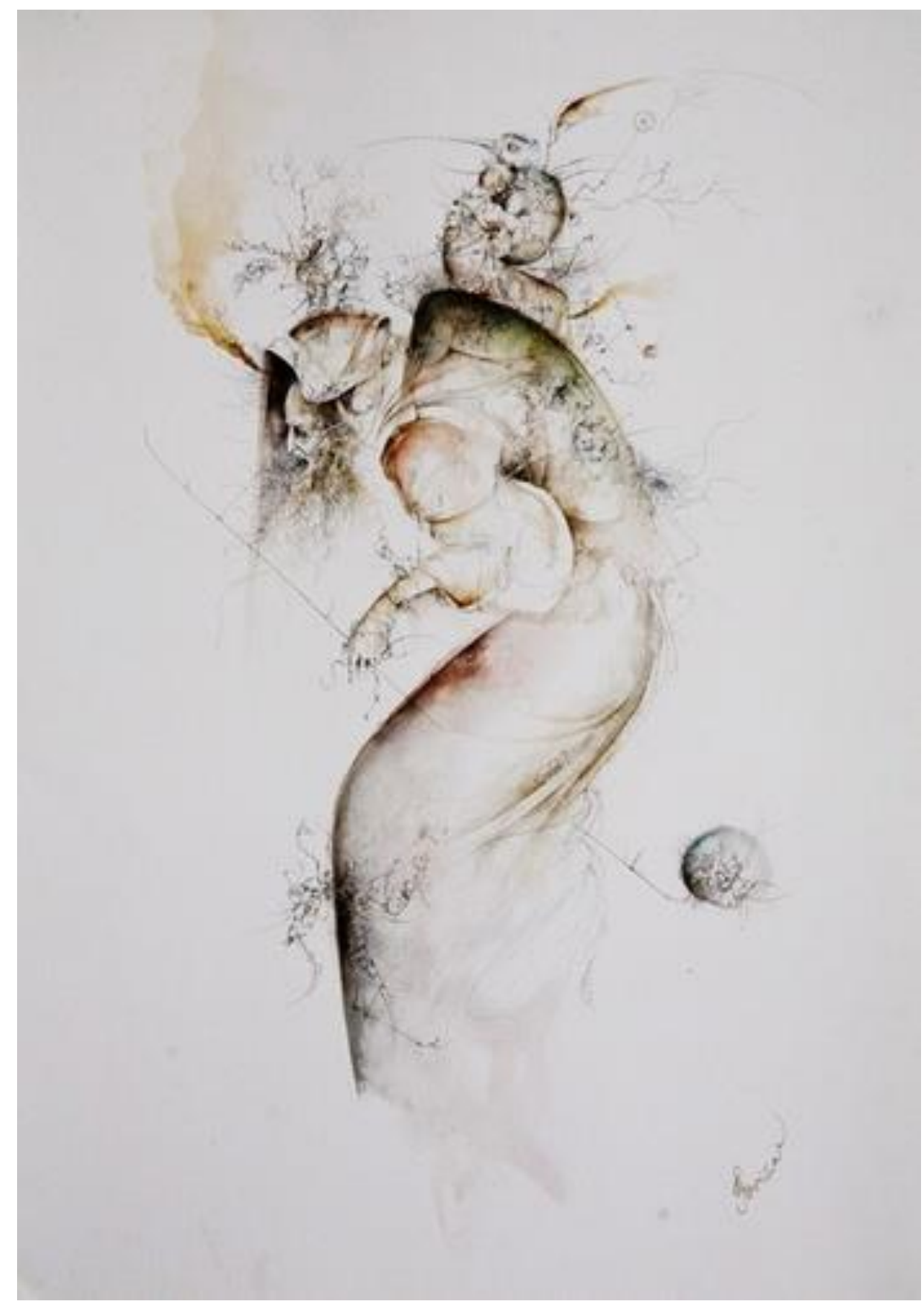

El Patriarca a la luz de las sefirot. J.L Fariñas. 2007

¿Es Abraham, Moisés u otro patriarca? Pero no importa el nombre sino la esencia. Expresa una síntesis de los patriarcas como un símbolo del espíritu del pueblo hebreo en sus éxodos; por lo que no es el patriarca que se espera: va como mal vestido, parece deshecho. Y en una obra dedicada a las sefirot, no pretende mostrarlas, ni siquiera su luz: solo efluvios metamorfoseados, la caída, la rotura, la simbiosis en miniaturas imperceptibles. 
Rutas interiores trata de la acción más importante del místico judío y practicante. Hay muchos modos esotéricos de buscar un entendimiento de qué es Dios y cuáles son los procesos de la creación. Aquí hay una figura que parece un pene y otra cosa que puede ser una costilla de una ostra; los dos forman parte de los procesos de la creación. El óvalo puede ser una perla o un huevo, resultados de la creación. En la obra de Fariñas, el huevo es casi siempre un símbolo de la vida, el futuro y la esperanza, pero es también un reciente roto.

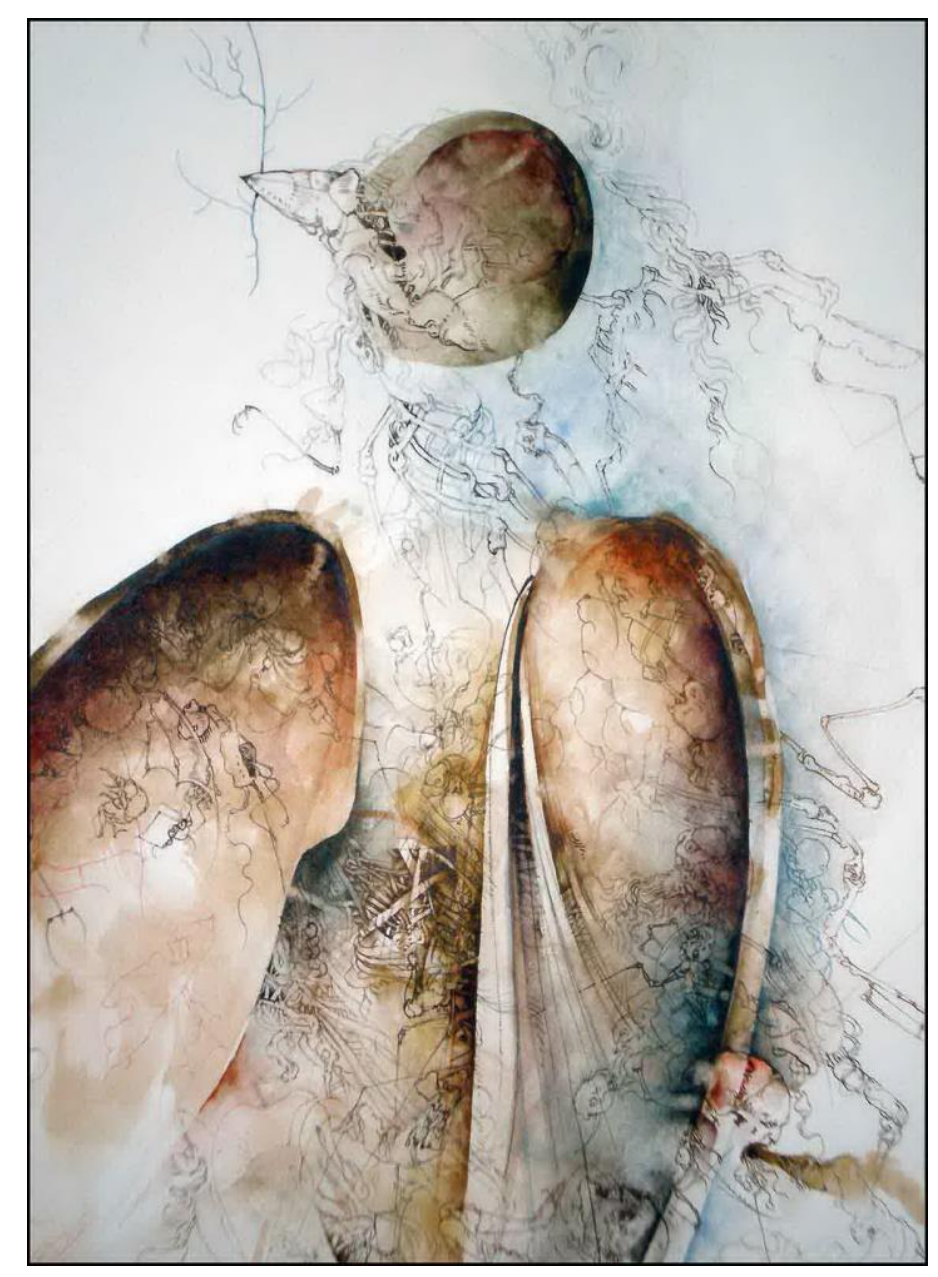

Rutas interiores. J. L. Fariñas, 2011

Cada cosa o persona lleva en sí infinitas contradicciones. Aquí las paradojas se confrontan y se imbrican. No hay balance. La curva a la izquierda es mucho más ancha, espesa y compleja que la derecha. Hay muchos elementos humanos. La curva derecha está en un estado de tensión con la otra. Tiene la misma forma, pero en el contenido, predominan cabezas y calaveras no bien formadas. Además, Fariñas, en otras obras, se concentra en la unión de opuestos. 


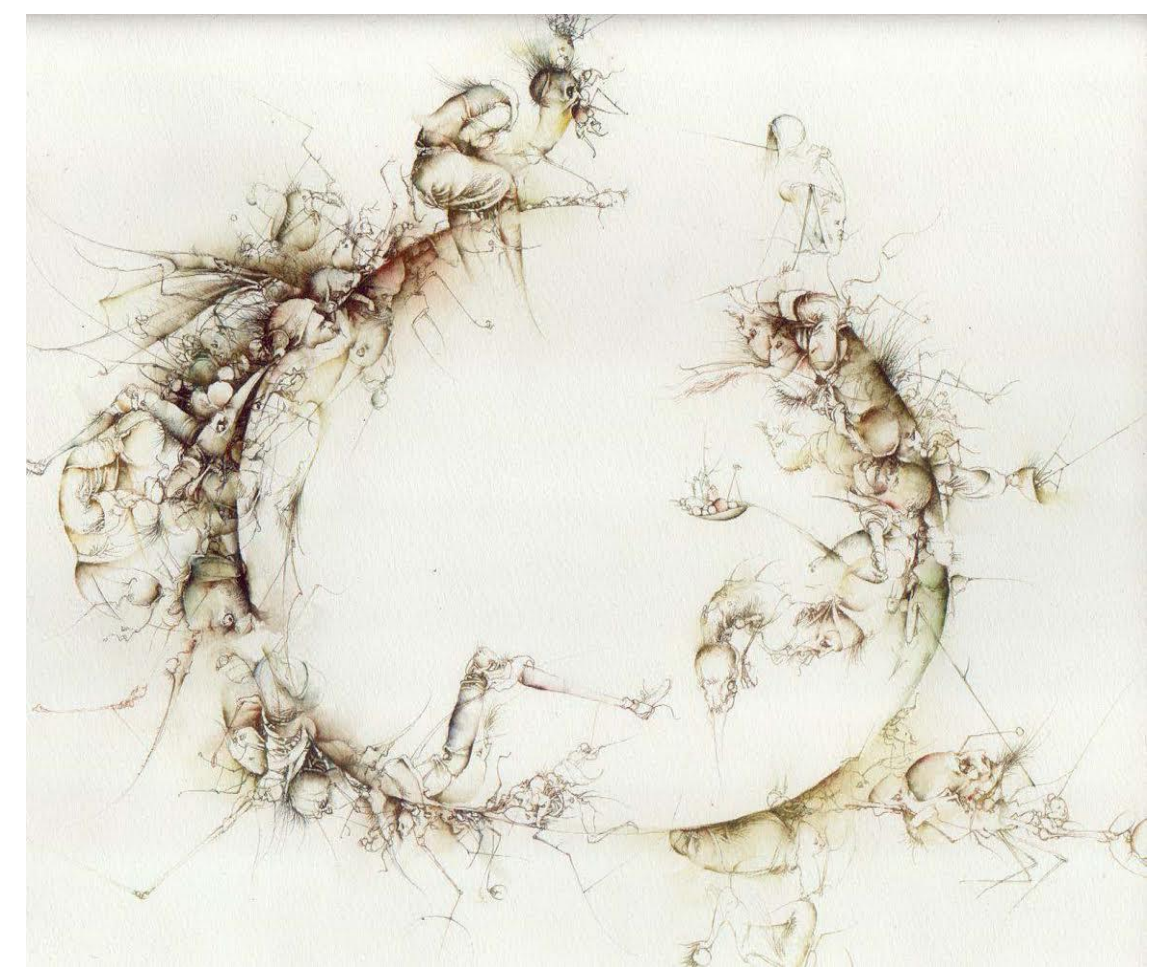

El milagro de las paradojas, J. L. Fariñas. 2005

En el Zohar (1:36b), la serpiente está descrita en términos sumamente negativas. Lleva baba consigo. Simultáneamente con Adán, embaraza a Eva, y por Caín, El Mal fue propagada a las generaciones futuras. El Leviatán de la Biblia es realmente una serpiente, no una ballena, y también un dragón (Isaías 27,1). Aquí se la ve con varias formas imaginadas. Tiene alas, cabeza y cola de un pájaro. Está en moción, y repetidamente curvada.

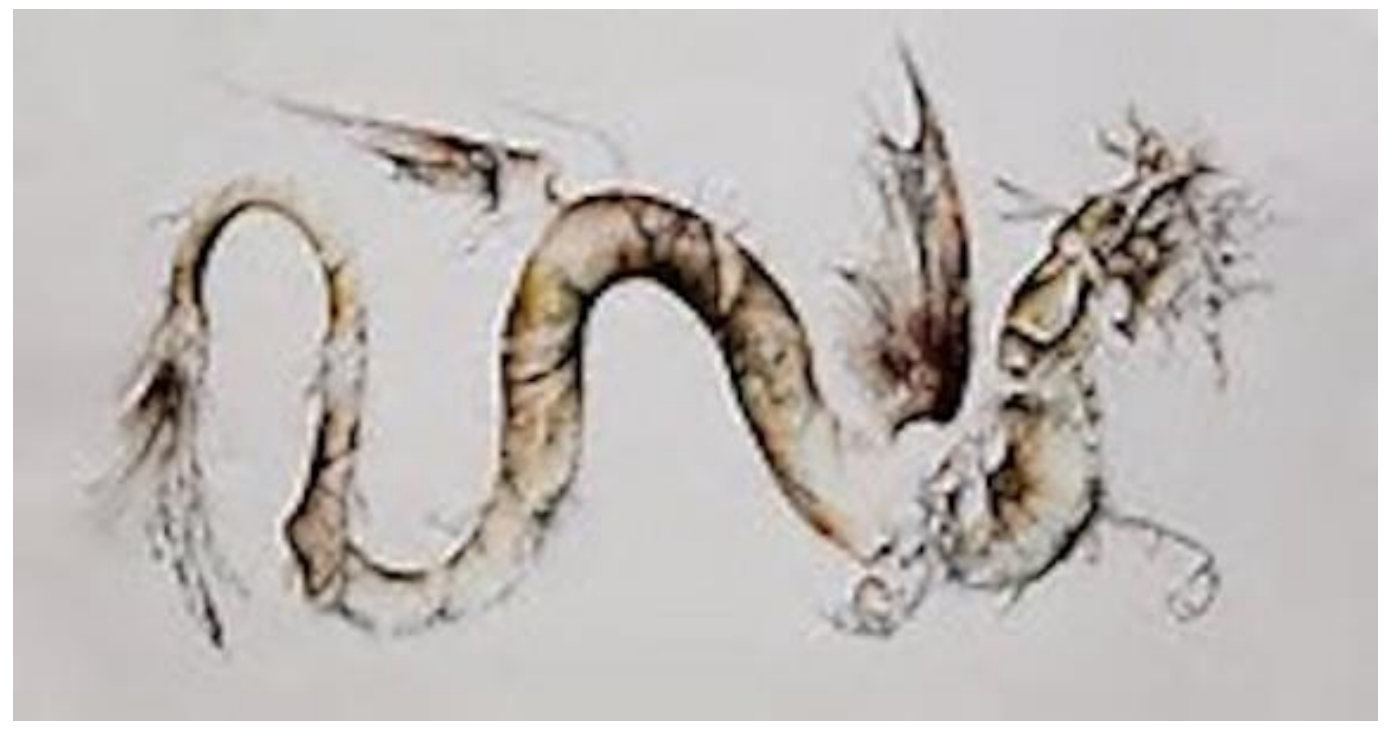


El serpiente del paraíso, J. L. Fariñas, 2007

La creación del mundo fue (o es) imperfecto. Al lado del Bien se encuentra el Mal. El ser humano tiene que reaccionar, hacer Ticún Olam, mejorar el mundo. En el arte de Fariñas, la Sitra Atra está presente con iconografía apocalíptica: hombres raros, y ángeles, diablos, bestias. (Collins, 280-4) En esta obra, hay un hombre furioso con humo saliendo de la boca. Lleva un yelmo. Apuntando hacia la dirección opuesta hay una ojiva o proyectil y un brazo humano. Abajo y a la derecha de esta obra está un huevo roto, sin signos de vida.

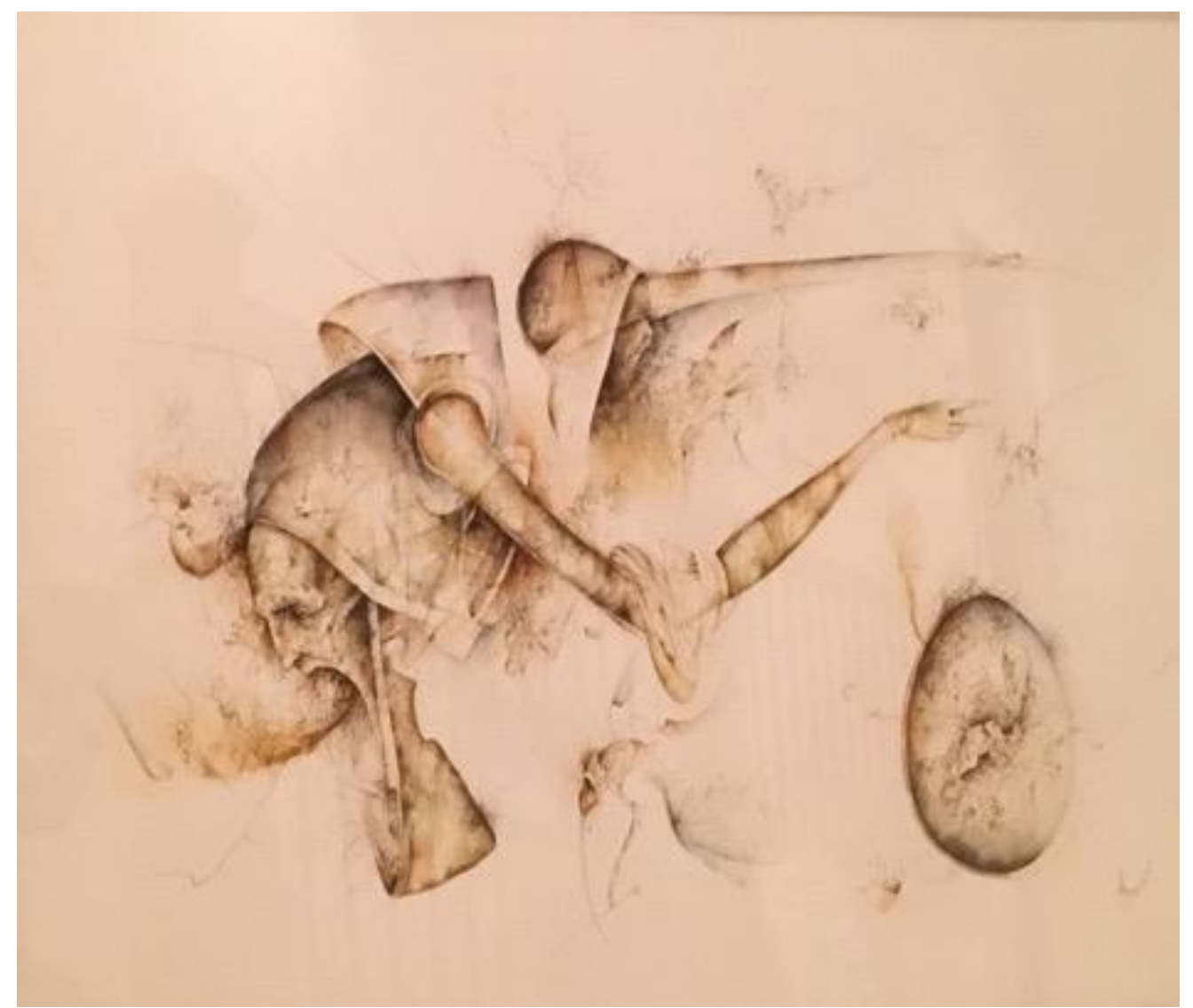

La Sitra Atra. J. L. Fariñas. 2007

La poesía de Fariñas es aún más hermética que el arte porque él casi nunca expresa directamente la temática judía. Sus alusiones y metáforas vienen de muchas culturas, como de la literatura clásica griega y romana o aun de la japonesa. No obstante, de vez en cuando, él intercala, como si fueran íntimos apartes al lector, estrofas con referencias judaicas.

El crítico cubano Alexander Pérez Heredia comenta, aunque no en términos cabalísticos: "En su poesía y narrativa. . . (p)alabra e imagen le sirven para penetrar la sustancia fugitiva e itinerante de la realidad y transgredir todas las leyes del espacio y el tiempo. Su obra, de una marcada espiritualidad, busca la experiencia totalizadora y se vale del símbolo para expresar las ideas en su sentido originario". (Pérez Heredia, p. 2) 
Dos ejemplos cabalísticos en la poesía de Fariñas:

Capa sobre capa se descubre el primer rostro de Dios, con sencillez, por entre líneas de aceite y de pigmentos que aglutinan las curvaturas de lo irrevelado. hasta dejarle asomar por entre el tejido de las antiguas aguas. (Fariñas, 2012, p. 13).

“La imagen es la única certeza, el artificio de la salvación.” (Fariñas, 2012, 15)

Un poema habla de una de las mil maneras de buscar la cara de Dios. La primera imagen es de una cebolla o de estratos de piedra. Hay contradicciones persistentes en la estrofa. "Lo irrevelado" no puede tener curvas. "La imagen es la única certeza" es una paradoja.

Vida y muerte funden sus ruedas. Lo más nuevo es lo más viejo; lo más distante, lo más próximo. (Fariñas, 2012, 15)

En esta estrofa, se notan otra vez las paradojas, encontradas y reencontradas por toda La Cábala desde el anciano Sefer Yetzirá. Las ruedas de la vida y la muerte se hacen una sola cosa.

\section{Conclusiones}

Juana García Abás es una poeta apasionante que ha creado su propio mapa del cosmos basado en textos místicos judíos esenciales, las interpretaciones de comentaristas antiguos y modernos y, hasta un cierto punto, las hipótesis y los descubrimientos de la física cuántica y la genética. La suya es la obra trascendente de una poeta mística judía, hispano-cubana y neo-marxista.

José Luis Fariñas es un artista visionario y profundamente cabalista, con un entendimiento de la Cábala muy personal. En su arte plástico su judaísmo predomina; en su poesía, está indicado de un modo expreso sólo en algunos versos, aparece tan sumergido como esencial en todos sus poemas.

Los dos presentan una visión artística única en la Cuba de hoy. Su obra es compleja y desafiante, pero también conmovedor y profunda.

\section{$\underline{\text { Bibliografía }}$}

Bedebia, Aricelys. 12 de abril de 2006. Juana García Abás. La literatura como una arma de las eficaces. Recuperado de: http://www.cubaliteraria.com/articulo.php?idarticulo=10531\&idseccion=43

Collins, John J. The Apocalyptic Imagination: An Introduction to Jewish Apocalyptic Literature, $2^{\text {nd }}$ edition. Grand Rapids, MI: William B. Eerdmans, 1998. 
John D. Dunn. Window of the Soul: The Kabbalah of Rabbi Isaac Luria. San Francisco: Weiser, 2008.

Fariñas, José Luis. "Breve introducción a la nada." El alma y la piedra, La Habana: Editorial Letras Cubanas, 2012, 15-17.

Fariñas, José Luis and Juana García Abás. "De lo evidente a lo sumergido: presencia de lo cabalístico." The Fine Brush Art Gallery of the Marcus Jewish Community Center of Atlanta, 2005, pp. 1-6.

García Abás, Juana. "Fariñas: fuego negro sobre fuego blanco." Revista Universidad de La Habana. vol. 256, 2002. pp. 64-68.

García Abás. Juana. Circunloquio. La Habana: Editorial Letras Cubanas, 2006.

---. "Fundamento Filosófico.” La Habana. 2015. Inédita. pp. 1-6. XX

García Marruz. Fina. "Una petisa del éxodo: En torno a Circunloquio, de Juana García Abás." La Habana, 2010. Inédita, p. 4.

Green, Arthur A. Guide to the Zohar. Berkeley: U of California P, 2003.

Kaplan, Aryeh. Sefer Yetzirah: The Book of Creation in Theory and Practice. Weiser, 1997.

López Lemos, Virgilio. 11 de noviembre de 2006. Circonloquios de Juana. Recuperado de: http://www.opushabana.cu/index.php/noticias/21-noticias-casa-de-papel/606-

Losada Guevara, Eugenio. 17 de julio de 2010. Cuestión de cábala y arbitrario: leyendo a Juana García Abás. Recuperado de:

http://archipielagodelapalabra.blogspot.com/2010/07/cuestion-de-cabala-y-arbitrio-leyendo.html

Maggid, Shaul. From Metaphysics to Midrash. Myth, History and the Interpretation of Scripture in Lurianic Kabbala. Indiana UP, 2008.

Muñiz-Huberman, Angelina. Las raíces y las ramas: Fuentes y derivaciones de la Cábala hebreahispana. Fondo de Cultura Económica, 2002.

Pérez Heredia, Alexander. "La aventura seminal de Fariñas." Revista Unión. La Habana. No. 49. 2003. pp.1-3.

Rae, Alistair I, M. Quantum Physics. Oxford UP, 2005.

Scholem, Gershom. Major Trends in Jewish Mysticism. New York. Schocken, 1974. 
Schwartz, Howard. 21 de marzo de 2011. "How the Ari Created Myth and Transformed Judaism" Recuperado de: http://www.tikkun.org/nextgen/how-the-ari-created-a-myth-and-transformedjudaism

The Zohar: Pritzker Edition. vol. 1. Traducido con notas de Daniel Matt. Stanford UP, 2003.

Wolfson, Elliot R. Through a Speculum that Shines: Vision and Imagination in Medieval Jewish Texts. Princeton UP, 1994.

Yoshinaga, Miyako.. 10 de febrero de 2013. “José Luis Fariñas: Soul's Documents” Recuperado de: http://www.cubartecontemporaneo.com/artwork/masterly-watercolours-jose-luis-farinas-vejezsabiduria/ 